\title{
Interactive comment on "Improved method of estimating temperatures at meteor peak heights" by Emranul Sarkar et al.
}

\section{Emranul Sarkar et al.}

emranul.sarkar@oulu.fi

Received and published: 22 February 2021

The comments are given in the supplementary file (attached pdf).

Please also note the supplement to this comment:

https://amt.copernicus.org/preprints/amt-2020-333/amt-2020-333-AC3-

supplement.pdf

Interactive comment on Atmos. Meas. Tech. Discuss., doi:10.5194/amt-2020-333, 2020. 